5. Zhu Q, Li D, Lai M, Chen X, Wei J, Zhang H, et al. Endovascular treatment of isolated abdominal aortic dissection and postoperative aortic remodeling. J Vas Surg 2015;61:1424-31.https://doi. org/10.1016/j.jvs.2015.01.027

6. Oikonoumou K, Kasprzak P, Katsargyris A, Marques de Marino P, Pfister K, Verhoeven E. Mid-Term Results of Fenestrated/ Branched Stent Grafting to Treat Post-dissection Thoraco-abdominal Aneurysms. Eur J Vasc Endovasc Surg2019;57,102-9. https://doi. org/10.1016/j.ejvs.2018.07.032

Rev Argent Cardiol 2020;88:362-365

http://dx.doi.org/10.7775/rac.v88.i4.18620

\section{Severe Pericardial Calcification: Does it Still Exist?}

Constrictive pericarditis is the final phase of a pericardial inflammatory process with progression to chronic involvement producing pericardial constriction and severe diastolic dysfunction. Only $1.8 \%$ of inflammatory pericarditis progress to constriction: postoperative pericarditis ranks first, followed by radiation-induced pericarditis and those caused by autoimmune diseases and infections.

Severe circumferential fibrosis and calcification are markers of adverse outcome and make the etiologic diagnosis difficult.

We describe the clinical and pathological findings of a case of pericardial constriction and cardiac osseous metaplasia in an immunocompetent patient.

A 58-year-old male patient with a history of hypertension and non-insulin-requiring diabetes mellitus visited the outpatient clinic due to edema of the lower extremities and class III dyspnea during the previous month. He was born in the province of Chaco in northeastern Argentina where he lived with his family in a poor home in overcrowded conditions.

On physical examination, his general status was poor, with cachexia and evident signs of advanced heart failure.

The electrocardiogram showed complete right bundle branch block with no other abnormalities. The laboratory tests revealed anemia, elevated liver enzymes and hypoalbuminemia. Serology tests for viral hepatitis $\mathrm{B}$ and $\mathrm{C}$ and $\mathrm{HIV}$ were negative, with positive tests for Chagas disease and a PPD test $<5 \mathrm{~mm}$.

The chest X-ray showed severe circumferential pericardial calcification (Figure $1 \mathrm{~A}$ ). The patient underwent Doppler echocardiography which confirmed the presence of pericardial calcification and signs of constriction. The chest computed tomography scan also

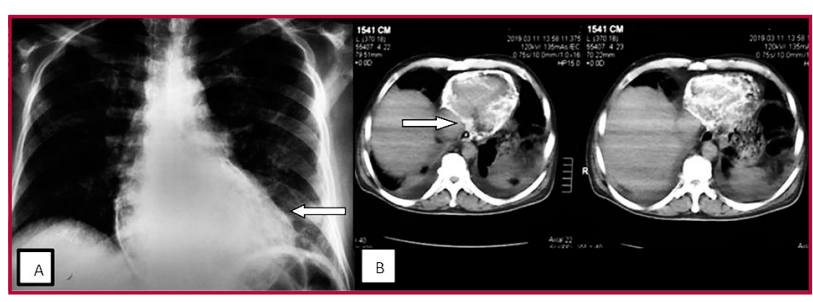

Fig. 1. A) Chest-X ray. B) Chest computed tomography scan with diffuse pericardial calcification (white arrows)

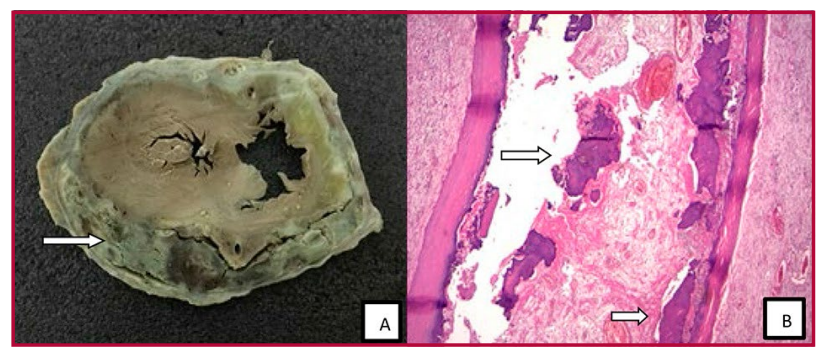

Fig. 2. A) Gross examination of the explanted heart with severe pericardial calcification. B) Optical microscopy image showing inflammatory infiltrate without granuloma and osseous metaplasia.

confirmed circumferential calcification of the pericardium with an "egg-shell" pattern (Figure 1B), and the presence of normal size calcified mediastinal, parahiliar, axillary and mesenteric lymph nodes.

A diagnosis of constrictive pericarditis was made, and after discussing the case in an interdisciplinary meeting, pericardiectomy was decided after improving the patient's general status, in terms of nutrition and heart failure.

Ten days after hospitalization the patient presented signs of multiple organ failure secondary to sepsis caused by a probable respiratory infection, and he finally died.

The autopsy report was chronic constrictive pericarditis, active and purulent, with pericardial areas of dystrophic calcification and osseous metaplasia (Figure 2).

Chronic constrictive pericarditis is rare and represents $1.8 \%$ of inflammatory pericarditis. (1) In Argentina, tuberculosis (TB) is the most common cause of pericardial constriction, but is a rare form of extrapulmonary TB, with a mortality rate of $60 \%$ when not treated. (2)

Pericardial involvement usually occurs from lymphatic spread of Mycobacterium tuberculosis, while hematogenous or contiguous spread from a primary pulmonary focus is uncommon.

The presence of fibrosis, pericardial calcification and osseous metaplasia reflect chronic and irreversible constriction. (3) The absence of active inflammation parameters (normal erythrocyte sedimentation rate and C-reactive protein and absence of leukocytosis) predict the lack of response to medical treatment.

Although these patients are candidates for surgical treatment (4), the main obstacle is the inability to remove calcium from the parietal pericardium, resulting in extremely high mortality (40\%) (5) associated with several factors: the poor general condition of these patients at the time of surgery, advanced age, advanced functional class (III-IV), presence of moderate to severe pericardial effusion and ascites, many of which were present in this patient.

Tuberculosis was the most likely etiology in our patient due to his living conditions and epidemiological environment. In our setting, TB is still a common cause of constrictive pericarditis and pericardial cal- 
cification but reports of osseous metaplasia are rare.

Medical treatment offers an alternative in early stages, but surgery is the only option for remission of the signs and symptoms of constriction. However, in cases such as the one presented by this patient, mortality is high due to the associated comorbidities and the advanced stage of the disease. Thus, these patients are still a therapeutic challenge nowadays.

\section{Conflicts of interest}

None declared.

(See authors' conflicts of interest forms on the website/ Supplementary material).

Ethical considerations

Not applicable

\section{Carolina Reynoso (D) , Mariela Tolusso, Mariano Napoli (iD , Andrea Zappi, Lucía R. Kazelian $\mathbb{D}$, Juan Gagliardi ic} Hospital General de Agudos "Dr. Cosme Argerich". Department of Cardiology. Email: carolina.gr91@live.com

\section{REFERENCES}

1. Nishimura R. Constrictive pericarditis in the moderna era: a diagnostic dilemma. Heart 2001;86:619-23. https://doi.org/10.1136/ heart.86.6.619

2. Porta Sanchez A, Sagristà-Sauleda J, Ferreira-González I, Torrents-Fernández A, Roca-Luque I, García-Dorado D, et al. Pericarditis constrictiva: espectro etiológico, presentaciones clínicas, factores pronósticos y seguimiento a largo plazo. Rev Esp Cardiol 2015; 68:1092-100. https://doi.org/10.1016/j.recesp.2014.12.019

3. Ling LH, Oh JK, Breen JF, Schaff HV, Danielson GK, Mahoney DW, et al. Calcific constrictive pericarditis: is it still with us? Ann Intern Med 2000;132:444-50. https://doi.org/10.7326/0003-4819-132-6200003210-00004

4. Adler Y, Charron P, Imazio M, Badano L, Barón-Esquivias G, Bogaert J, et al. Guía ESC 2015 sobre el diagnóstico y tratamiento de las enfermedades del pericardio. Rev Esp Cardiol 2015; 68:1126.e1e46 https://doi.org/10.1016/j.recesp.2015.10.011

5. Bertog SC, Thambidorai SK, Parakh K, Schoenhagen P, Ozduran V, Houghtaling PL, et al. Constrictive pericarditis: etiology and cause-specific survival after pericardiectomy. J Am Coll Cardiol 2004;43:1445-152. https://doi.org/10.1016/j.jacc.2003.11.048

Rev Argent Cardiol 2020;88:365-366

http://dx.doi.org/10.7775/rac.v88.i4.18616 